\title{
Mathematical Modelling for a Multi-Product Inventory Routing Problem with Split Delivery
}

\author{
Yuling Yeh1, Chinyao Low ${ }^{2 *}$ \\ ${ }^{1}$ Department of Marketing and Logistics, Nan-Kai University of Technology, Taiwan \\ ${ }^{2}$ Department of Industrial Engineering and Management, National Yunlin University of Science and Technology, Taiwan \\ Email: yip@nkut.edu.tw, *lowcy@yuntech.edu.tw
}

How to cite this paper: Yeh, Y.L. and Low, C.Y. (2017) Mathematical Modelling for a Multi-Product Inventory Routing Problem with Split Delivery. Journal of Applied Mathematics and Physics, 5, 1607-1612. https://doi.org/10.4236/jamp.2017.59132

Received: June 9, 2017

Accepted: September 12, 2017

Published: September 15, 2017

\begin{abstract}
In this article, a multi-product inventory routing problem is studied. One-depot and many retailers in a finite time period are considered, and split delivery is allowed as well for the addressed problem. The objective is to minimize the overall cost including vehicle cost, inventory holding cost and transportation cost while the delivery schedule and the quantity of each product for each retailer have to be decided simultaneously. A mathematical model is presented for solving the addressed optimally and example is illustrated as well.
\end{abstract}

\section{Keywords}

Inventory Routing Problem, Split Delivery, Mathematical Model

\section{Introduction}

Transportation and inventory costs are the two main components of a supply chain. Both transportation and inventory costs ought to be considered concurrently in the logistic planning functions as these two areas might lead to significant gains and more competitive distribution strategies (Moin et al. 2011). Although this is a well known fact that approaches for supply chain optimization usually consider inventory control and transportation independently, the interrelationship between these two components is always ignored. The coordination of these two drivers, often known as the inventory routing problems (IRPs), is critical in improving the supply chain management (SCM). IRP has been studied for the last decades, for the single item IRP such as [2] [3] [8] [9] [10], and for the MIRP [1] [4] [5] [6] [7] [11] [12] [13] [14] as well. However, fewer of the researches take the split delivery issue into account [4] [5] [10]. 


\section{Problem Description and Assumption}

Consider one distribution center (DC, as the depot) and many customers in a supply chain system. The DC is responsible to deliver different products to meet the demands in each customer in finite time horizon without backorder. There are limited storage capacity shared by all the products in DC and customers. The manager of the supply chain in DC has full information of the inventory level and future demands of each customer. The holding cost happens in both sides. A homogeneous fleet of vehicles with limited capacity to deliver all the products and split delivery is allowed. The total cost includes holding cost, the fixed cost of vehicle using and flexible cost of traveling distances. The manager has to decide simultaneously the quantities of different products to deliver to each customer in the planning horizon, how many vehicles to use, and the route of each vehicle whereas minimizing the total cost.

To simplify the formulation for the proposed mixed integer programming (MIP) model, some assumptions are described as follows.

(1) The DC has sufficient inventory to meet all the demands.

(2) All the demands are deterministic.

(3) Each product has the same volume and weight.

(4) Leading time is not considered.

(5) No time window for transportation is considered.

(6) There are sufficient vehicles to satisfy the routing decision.

(7) The traveling distance matrix is symmetric and known.

\section{Model Formulation}

\subsection{Notations}

$V$ : Set of nodes. 0 is the depot (DC); others are customers (retailers).

$V^{\prime}: V^{\prime}=V \backslash\{0\}$.

$i, j:$ Indices of nodes. $i, j \in V$.

$p$ : Index of the product. $P$ is the set of all products. $p \in P$.

$k, h$ : Indices of the vehicle. $K$ is the set of all vehicles. $k, h \in K$.

$t$ : Index of the time period. $T$ is the set of all time periods. $t \in T$.

$h_{i p}$ : Unit holding cost of product $p$ at node $i$. It is constant throughout the planning time horizon.

$L_{i p t}$ : Inventory level of product $p$ at node $i$ in the end of time $t$.

$R_{p t}$ : The available quantity of product $p$ from suppliers at depot 0 in the beginning of time $t$.

$D_{i p t}$ : The demand of product $p$ at node $i$ in the end of time $t$.

$R C_{i}$ : Storage capacity of node $i$. It is shared by all products.

$V C_{k}$ : Vehicle capacity.

$C_{i j}$ : Unit distance cost from node $i$ to node $j$.

$M$ : A extremely big number.

$F C$ : Fixed cost of vehicle used. 
$S_{i p k t}$ : Shipping quantity of product $p$ of node $i$ by vehicle $k$ in time $t$.

$T K S_{i k t}$ : Total shipping quantity of node $i$ by vehicle $k$ in time $t$.

$T S_{i t}$ : Total shipping quantity of node $i$ in time $t$.

$W_{k t}$ : Binary variable. It equals 1 if and only if vehicle $k$ is used in time $t, 0$ otherwise.

$U_{i j k t}$ : The flow of vehicle $k$ traveling from node $i$ to node $j$ in time $t$.

$T K S_{i k t}$ : Fraction of the shipping quantity of node $i$ by vehicle $k$ in time $t$.

$X_{i j k t}$ : Binary variable. It equals 1 if and only if vehicle $k$ from node $i$ to node $j$ in time $t, 0$ otherwise.

\subsection{Model}

\section{Minimize}

$$
\begin{aligned}
& \sum_{i \in V} \sum_{p \in P} \sum_{t \in T} H C_{i p} \times L_{i p t}+\sum_{i \in V} \sum_{j \in V} \sum_{k \in K} \sum_{t \in T} C_{i j} \times X_{i j k t}+\sum_{k \in K} \sum_{t \in T} W_{k t} \times F C \\
& L_{0 p t}=L_{0 p(t-1)}+R_{p t}-\sum_{i \in V^{\prime}} \sum_{k \in K} S_{i p k t} \quad \forall p \in P, \quad t \in T>0 \\
& L_{i p t}=L_{i p(t-1)}+\sum_{k \in K} S_{i p k t}-D_{i p t} \quad \forall i \in V^{\prime}, \quad \forall p \in P, \quad t \in T>0 \\
& \sum_{p \in P} L_{i p t} \leq R C_{i} \quad \forall i \in V, \quad t \in T \\
& \sum_{p \in P} \sum_{k \in K} S_{i p k t} \leq R C_{i}-\sum_{p \in P} L_{i p(t-1)} \quad \forall i \in V^{\prime}, \quad t \in T>0 \\
& \sum_{p \in P} S_{i p k t}=T K S_{i k t} \quad \forall i \in V^{\prime}, \quad \forall k \in K, \quad t \in T \\
& \sum_{p \in P} T K S_{i k t}=T S_{i t} \quad \forall i \in V^{\prime}, \quad t \in T \\
& \sum_{j \in V} X_{i j k t}-\sum_{j \in V} X_{j i k t}=0 \quad \forall i \in V^{\prime}, \quad \forall k \in K, \quad t \in T \\
& \sum_{k \in K} F_{i k t}=1 \quad \forall i \in V^{\prime}, \quad t \in T \\
& \sum_{i \in V^{\prime}} T S_{i t} \times F_{i k t} \leq V C_{k} \quad \forall k \in K, \quad t \in T \\
& \sum_{j \in V} X_{j i k t} \geq F_{i k t} \quad \forall i \in V^{\prime}, \quad \forall k \in K, \quad t \in T \\
& \sum_{j \in V} U_{j i k t}-\sum_{j \in V} U_{i j k t}=T K S_{i k t} \quad \forall i \in V^{\prime}, \quad \forall k \in K, \quad t \in T \\
& \sum_{j \in V} U_{j i k t}-\sum_{j \in V} U_{i j k t}=T S_{i t} \times F_{i k t} \quad \forall i \in V^{\prime}, \quad \forall k \in K, \quad t \in T \\
& U_{i j k t} \leq X_{i j k t} \times V C_{k} \quad \forall i, j \in V, \forall k \in K, \quad t \in T \\
& \sum_{i \in V} \sum_{j \in V} X_{i j k t} \leq M \times W_{k t} \quad \forall k \in K, t \in T \\
& W_{h t} \leq W_{k t} \quad \forall h, k(h>k) \in K, \quad t \in T \\
& U_{i 0 k t}=0 \quad \forall i \in V^{\prime}, \forall k \in K, t \in T \\
& X_{\text {iikt }}=0 \quad \forall i \in V, \forall k \in K, \quad t \in T
\end{aligned}
$$




$$
\begin{gathered}
L_{i p t} \geq 0 \quad \forall i \in V, \forall p \in P, \quad t \in T \\
S_{i p k t}, T K S_{i k t}, T S_{i t}, D_{i p t} \geq 0 \quad \forall i \in V^{\prime}, \quad \forall p \in P, \forall k \in K, \quad t \in T \\
W_{k t}, \quad X_{i j k t}=\{0,1\} \quad \forall i, j \in V, \quad \forall k \in K, \quad t \in T
\end{gathered}
$$

The objective function (1) minimizes the total cost, including inventory cost, traveling distance cost and vehicle using cost. Constraints (2) and (3) ensure the inventory balance at depot and customers while constraints (4) define the maximum inventory capacity. Constraints (5) state the total shipping quantity of each customer is not over the remaining inventory capacity. Constraints (6) and (7) link the shipping quantity to the vehicle routing variables. Constraints (8) ensure the same vehicle arrives and leaves the customer served. Constraints (9) make sure each customer served by at least one vehicle receives its full planned shipment in each time period. Constraints (10) limit the delivery quantity to vehicle capacity while constraints (11) permit each customer to be served by more than one vehicle. Constraints (12) and (13) are the flow balance constraints and eliminate the sub-tours. Constraints (14) ensure the flow is not over the vehicle capacity when traveling between two nodes. Constraints (15) state the customers can be served only by the vehicle which is used. Constraints (16) say the vehicle using order. Constraints (17) ensure there is no product when the vehicle returns to the depot. Constraints (18) prohibit the same vehicle back to the same customer served. Constraints (19) and (20) state the non-negative integer variables while constraints (21) define the binary variables.

\section{Example Illustration}

For a MIRP problem, one distribution center and two customers (C1, C2) with two products $(\mathrm{P} 1, \mathrm{P} 2)$ are considered. The planning horizon is 3 days. The inventory and demand information, and distance matrix are given in Table 1 and Table 2, respectively. The storage capacity of the DC and retailers are 999, 20, 20. The available amount of P1 and P2 from suppliers are 20, 20 in each period. Holding cost of P1 and P2 in DC are both 0.01 and in customers are 0.05 and 0.08 . There are three homogenous vehicles with 10 units of capacity in each day. Unit cost of traveling distance is 1 while fixed cost of vehicle using is 5 .

The addressed problem is solved by the Lingo 11 . The total cost is obtained as 98.6, and the results are summarized in Table 3 and Table 4, and the routes in each day are shown in Figure 1 as well.

Table 1. Initial inventory and demand information of DC and customers.

\begin{tabular}{ccccccc}
\hline & DC-P1 & DC-P2 & C1-P1 & C1-P2 & C2-P1 & C2-P2 \\
\hline Initial stock & 5 & 5 & 6 & 5 & 8 & 9 \\
Day1 demand & 0 & 0 & 6 & 5 & 8 & 9 \\
Day1 demand & 0 & 0 & 6 & 5 & 8 & 9 \\
Day1 demand & 0 & 0 & 6 & 5 & 8 & 9 \\
\hline
\end{tabular}


Table 2. Distance matrix.

\begin{tabular}{cccc}
\hline & DC & C1 & C2 \\
\hline DC & - & 10 & 8 \\
C1 & 10 & - & 5 \\
C2 & 8 & 5 & - \\
\hline
\end{tabular}

Table 3. Delivery quantity for the addressed example.

\begin{tabular}{ccccccc}
\hline Delivery quantity & DC-P1 & DC-P2 & C1-P1 & C1-P2 & C2-P1 & C2-P2 \\
\hline Day1 & 0 & 0 & 0 & 0 & 0 & 0 \\
Day2 & 0 & 0 & 6 & 5 & 10 & 9 \\
Day3 & 0 & 0 & 6 & 5 & 6 & 9 \\
\hline
\end{tabular}

Table 4. Stock level for the addressed example.

\begin{tabular}{ccccccc}
\hline Stock level & DC-P1 & DC-P2 & C1-P1 & C1-P2 & C2-P1 & C2-P2 \\
\hline Day1 & 25 & 25 & 0 & 0 & 0 & 0 \\
Day2 & 29 & 31 & 0 & 0 & 2 & 0 \\
Day3 & 37 & 37 & 0 & 0 & 0 & 0 \\
\hline
\end{tabular}

Dayl: no delivery in day 1

Day2:
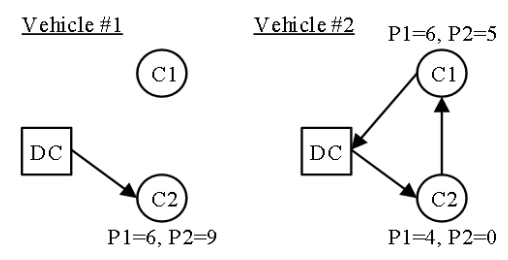

Day3:

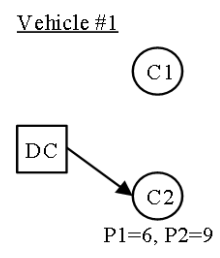

Vehicle \#2 $\mathrm{P} 1=6, \mathrm{P} 2=5$

Figure 1. Vehicle routes for the addressed example.

\section{Conclusion}

In this article, a mathematical model is proposed for solving MIRP problem with split delivery allowed. Although the proposed model can solve the addressed problem optimally, it is run time consuming with the problem scale increasing. Therefore, some meta-heuristics such as genetic based algorithms, particle swarming can be applied in the future study for solving the large scale problem.

\section{References}

[1] Abdelmaguid, T.F. and Dessouky, M.M. (2006) A Genetic Algorithm Approach to the Integrated Inventory-Distribution Problem. International Journal of Production Research, 44, 4445-4464. https://doi.org/10.1080/00207540600597138

[2] Archetti, C., Bertazzi, L., Hertz, A. and Speranza, M.G. (2012) A Hybrid Heuristic for an Inventory-Routing Problem. INFORMS Journal on Computing, 24, 101-116. 
https://doi.org/10.1287/ijoc.1100.0439

[3] Archetti, C., Bertazzi, L., Laporte, G. and Speranza, M.G. (2007) A Branch-and-Cut Algorithm for a Vendor-Managed Inventory-Routing Problem. Transportation Science, 41, 382-391. https://doi.org/10.1287/trsc.1060.0188

[4] Bell, W.J., Dalberto, L.M., Greenfield, A.J., Jaikumar, R., Kedia, P., Mack, R.G. and Prutzman, P.J. (1983) Improving the Distribution of Industrial Gases with an On-line Computerized Routing and Scheduling Optimizer. Interfaces, 13, 4-23. https://doi.org/10.1287/inte.13.6.4

[5] Bertazzi, L., Speranza, M.G. and Ukovich, W. (1997) Minimization of Logistic Costs with Given Frequencies. Transportation Research Part B, 31, 327-340. https://doi.org/10.1016/S0191-2615(96)00029-X

[6] Coelho, L.C., and Laporte G. (2013) A Branch-and-Cut Algorithm for the Multi-Product Multi-Vehicle Inventory-Routing Problem. International Journal of Production Research, 51, 7156-7169. https://doi.org/10.1080/00207543.2012.757668

[7] Coelho, L.C. and Laporte G. (2014) Optimal Joint Replenishment, Delivery and Inventory Management Policies for Perishable Products. Computers and Operations Research, 47, 42-52. https://doi.org/10.1016/j.cor.2014.01.013

[8] Federgruen, A. and Zipkin, P. (1984) A Combined Vehicle Routing and Inventory Allocation Problem. Operations Research, 32, 1019-1037.

https://doi.org/10.1287/opre.32.5.1019

[9] Hewitt, M., Nemhauser, G., Savelsbergh, M. and Song, J. (2013) A Branch-and-Price Guided Search Approach to Maritime Inventory Routing. Computers and Operations Research, 40, 1410-1419. https://doi.org/10.1016/j.cor.2012.09.010

[10] Huang, S.H. and Lin, P.C. (2010) A Modified Ant Colony Optimization Algorithm for Multi-Item Inventory Routing Problems with Demand Uncertainty. Transportation Research Part E, 46, 598-611. https://doi.org/10.1016/j.tre.2010.01.006

[11] Liu, S. and Lee, W. (2011) A Heuristic Method for the Inventory Routing Problem with Time Windows. Expert Systems with Applications, 38, 3223-3231. https://doi.org/10.1016/j.eswa.2011.04.138

[12] Moin, N.H., Salhi, S. and Aziz, N.A.B. (2011) An Efficient Hybrid Genetic Algorithm for the Multi-Product Multi-Period Inventory Routing Problem. International Journal of Production Economics, 133, 334-343. https://doi.org/10.1016/j.ijpe.2010.06.012

[13] Popović, D., Vidović, M. and Radivojević, G. (2012) Variable Neighborhood Search Heuristic for the Inventory Routing Problem in Fuel Delivery. Expert Systems with Applications, 39, 1390-1398. https://doi.org/10.1016/j.eswa.2012.05.064

[14] Vidović, M., Popović, D. and Ratković, B. (2013) Mixed Integer and Heuristics Model for the Inventory Routing Problem in Fuel Delivery. International Journal of Production Economics, 147, 593-604. https://doi.org/10.1016/j.ijpe.2013.04.034 
Submit or recommend next manuscript to SCIRP and we will provide best service for you:

Accepting pre-submission inquiries through Email, Facebook, LinkedIn, Twitter, etc. A wide selection of journals (inclusive of 9 subjects, more than 200 journals)

Providing 24-hour high-quality service

User-friendly online submission system

Fair and swift peer-review system

Efficient typesetting and proofreading procedure

Display of the result of downloads and visits, as well as the number of cited articles Maximum dissemination of your research work

Submit your manuscript at: http://papersubmission.scirp.org/

Or contact jamp@scirp.org 